\title{
ICT education in Fiji, issues and challenges faced by tertiary education sector: an empirical survey
}

\author{
Shareeni Shashi Kala \\ Computing Science and Information System, School of Mathematical and Computing Sciences Fiji National University, Suva, Fiji
}

Email address:

shareeni.kala@fnu.ac.fj, shareeni.kala@yahoo.com

To cite this article:

Shareeni Shashi Kala. ICT Education in Fiji, Issues and Challenges Faced by Tertiary Education Sector: An Empirical Survey. Education Journal. Vol. 2, No. 3, 2013, pp. 91-97. doi: 10.11648/j.edu.20130203.16

\begin{abstract}
The world moving rapidly into digital media and information, thus ICT education is becoming more and more important and this importance will continue to grow and develop into this century. This research would provide significant contribution to education sector by identifying various issues and challenges and challenges faced by education sector in conducting ICT education focused on tertiary level education. The primary data from three main tertiary education providers will be collected and estimate the models on information technology hours and determinant of personal computers or laptop usage.
\end{abstract}

Keywords: ICT, Education, ICT Performance, ICT Hours

\section{Introduction}

In this competitive educational environment, globalization and rapid technological change have made knowledge a critical determinant of it. There needs to be important role in assisting countries in taking advantage of the opportunities in information and communications technologies (ICTs) to contribute to education goals. In this age of globalization, the information revolution, and increasing demands for a highly skilled workforce, it is clear that nations must accord high priority to building the capacity to effectively utilize technology in education. One such instance would be involvement telecommunications authorities for the national level policies for the infrastructure base ICT developments (Ajayi, 2002).

It is therefore a need to look into the critical importance of effectively utilizing new information and communication technologies to meet the growing need for a more sophisticated labor force, manage information systems, and contribute to most of the odds such as hunger, education crisis, child exploitation or the poverty in total. The Information Communication Technology (ICT) in education includes assistance for equipment and facilities, teacher training and support, capacity building, educational content, distance learning, digital literacy, policy development, monitoring and evaluation and public and media involvement. ICT is said to be indispensible where developing of learning is concern home, work, organization and country (Yusuf, 2005).

Most government and funding agencies such as World Bank is involved insystematically examine and strengthen the performance of their education systems to achieve learning for all through the use of ICTs in educational settings around the world

(www.worldbank.org/education/saber-ict, accessed on 25th February 2013). One such example is from United States (US), where the student information systems ${ }^{1}$ from different districts have enable the schools to access to student records in the real-time for enrollment and attendance. The schools in US are able to make better decision-making with the electronic data systems which provides benchmarking assessment data, allows data warehouse for current and historical data and formulate reports for instructional or curriculum management system.

The use of technology in education has been steadily growing globally. The increasingly ubiquitous nature of modern technology, specifically computers, and the use of technology in the classroom broke the boundary of ICT subjects and technology introduced in other subjects. One will be able to see simultaneous growth inside the core subject and other subjects. The new technology introduced enables useful tool in the regular classroom where dynamic

\footnotetext{
${ }^{1}$ U.S. Department of Education, Office of Planning, Evaluation, and Policy Development, Use of Education Data at the Local Level From Accountability to Instructional Improvement, Washington, D.C., 2010. Report is on website at http://www.ed.gov/about/offices/list/opepd/ppss/reports.html\#edtech
} 
educators were looking for ways to improve their presentation of material, engage students, and provide current and relevant information (Jhurree, 2005).The process of teaching has since been undergoing its own revolution, or evolution, from fact-focused and dependent upon lectures and demonstrations to a cognitive process focusing on critical thinking and problem solving. There is a shift for learners from what they know to what is accessible and stored as an added benefit.

\section{Literature and Methodology}

Information Communication Technologies have enormous potential to benefits in terms of enhanced income-generation opportunities, education, political empowerment, access to resources and information and communication with a world outside the boundaries of home, employment and improved quality of life (Marcella, 2002).

Trucana (2005) also agreed that there is a widespread belief that will empower teachers and learners, transforming teaching and learning processes from being highly teacher dominated to student centered and that this transformation will result in increased learning gains for students, creating and allowing for opportunities for learners to develop their creativity, problem solving abilities, informational reasoning skills, communication skills and other high order thinking skills. It is believed that specific uses of ICT have positive effects on student achievement when ICT's are used appropriately to complement a teacher's existing pedagogical. However, (Pak, 2006) said that educational software is expensive, especially the sophisticated ones, and time consuming to develop.

Uses of ICTs for stimulations and modeling in Science and Math have been shown to be effective, as have word processing and communication software (email) in the development of student language and communication skills. Students who use a computer at home also use them in school more frequently and with more confidence than those who have no home access (Trucana, 2005).Computer Aided (or Assisted) Instruction (CAI) which refers generally to student self-study or tutorials on computers, has been shown to slightly improve student test scores on some reading and math skills, although whether such improvement correlates to real improvement in student learning.

This was supported by Anju \& Vikas (2012) saying that ICT helps to educate through electronic mediated learning. They look at ICT and IT as immediacyin education. Distance education can enable learners who don't have physical access to schools to participate through online, radio or any other ICT tool in education classes. E-learning, this can involve a wide variety of technologies such as DVD, CD-ROM, or internet, offer student's access to a vast amount of information and resources that is not possible in a single instructional setting for the learner-centered or self- paced and more into problem solving environment(Larsen \& Vincent-Lancrin, 2005).

The research method adopted will be questionnaires and interviews. Adequate sample size of tertiary institutions would be surveyed for data collection. Total of six hundred and forty (640) questionnaires was filled by three (3) tertiary institutions; namely University of the South Pacific, Fiji National University and University of Fiji. The result from the questionnaires is analyzed with challenges in the ICT hours where the student age, gender, education type, computer ownership and the availability of computer per student is factor. The second area is the Education performance with the factors to consider of self-directed learning hours by each student the ICT hours, and the entry level marks from secondary education. Finally the education performance is evaluated in terms of the grade average in the previous term of study.

This study is based on presence of ICT in the secondary and tertiary institutes and it is to determine the direct and indirect impacts on students spending quality time and evaluating the performance either in the ICT subject or not ICT subjects.

This research was targeted towards the local university students who have just started the experience of tertiary education and some are just started to use ICT component into their daily learning. There were vast many students who took the questionnaire but due to limited or no access to ICT have not answered the questionnaire. The data collection was open and answered questionnaires were later discarded before analysis of the data

\section{Empirical ICT Survey Result}

The tertiary level education in Fiji starts mostly from fourteenth year of education and average age of nineteen years. Two of the local university is higher education institute where only successful year thirteen is enrolled. Generally, year twelve or thirteen successful school leavers take up the studies in the three universities in Fiji. There was $50 \%$ student participation from Fiji National University, $24 \%$ from the University of South Pacific and 26\% from University of Fiji. The survey reveals three general areas of studies namely; Science (agriculture, applied science, engineering, medicine and technology), Arts (business, hospitality, management, accounting, and economics) and Humanities (social science, literature and creative arts).

There were $46 \%$ male and $54 \%$ female participation where $36 \%$ students were first year tertiary level students and $27 \%$ final year students. The $26 \%$ of the students were matured students study at tertiary level and $0.3 \%$ have not complete year twelve and gained entry in tertiary education by the work experience and courses during work experience. This is given priority as two university give opportunity to access work-based learning or home-based learning (Hong \& Songan, 2011) where flexibility to students are given electronic-learning (e-learning) medium. The $48 \%$ of the participants are working students. ICT as a 
tool (Mlitwa, 2007) has generally enabled the working students to study in tertiary institutions to advance knowledge and using ICT as the domain of knowledge.

There were $83 \%$ students who have successfully completed the secondary education and gained an entry at the higher education programmes in the three universities. This indicates that $73 \%$ of the young people between the ages of the 18-22 years are into the tertiary learning or lifelong learning (Scheuermann, 2009). Students in this survey showed that $64 \%$ owned a computer or a laptop. The ICT emergence as a learning technology is picked up in the higher education environment (Oliver, 2000). Hattangdi\&Ghosh (2008) state that mobile learning and other seamless learning is enabled with the integration of ICT in most of the universities which enables real time and delayed participation with the students using computers.

\section{Impact on Time Students Spend on ICT Usage}

The factor for how much hours are spent is the age groups, education type, gender, PC ownership in this study. The study shows variation in how students have responded to the Self Directed Hours spent in campus related work. The majority of the students belong to category of 1-10 hours where $76 \%$ students responded positively. For the student to spend more than twenty and more hours on campus, only $8 \%$ responded. The Age group reflected on the age of 18-21 years and these were students enrolled after completing the secondary level education. The computer literacy and subjects in tertiary programmes reveals in Figure 1 that most student have taken computing in year 12 and 13, while in university while at work:

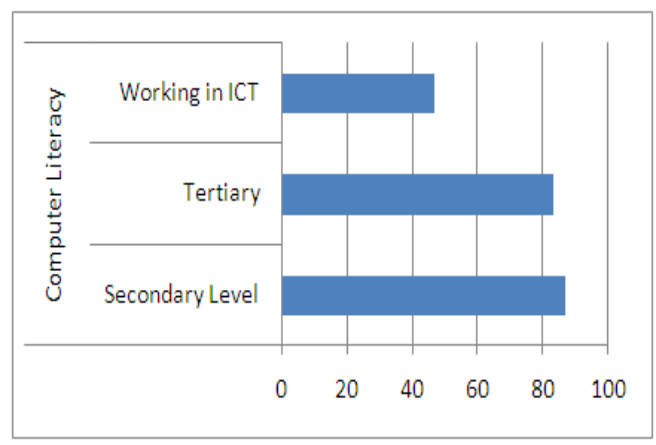

Figure 1. Computer Literacy

The student engagement in ICT subject has integrated well in the secondary education and student in tertiary are getting well exposed to Information Technologies, from the point of view of their possible relation with some aspects of the student engagement (Kuh \& Nelson, 2004). The gender variation is not too much but there are more females $(52 \%)$ who have responded to be in the ICT engagement. The trend of first year students to have more female is more inclined for the female student taking certificate or diploma level education for shorter time to complete studies in the one of the university, Fiji National University.

The survey found that students are well equipped to come into tertiary education with the computer, laptop and access to a computer. There were $64 \%$ students who are from mixed subject area responded that they own a computer while other $21 \%$ would need to depend on the computers in university. There was still approximately, $8 \%$ student who did not have access, own or were finding it difficult to access a computer freely. Notably, the age of computer is also reflecting that most students use the new computers as $65 \%$ students had their ICT equipment between 1-3years old.

The students have just the ICT time spent on campus as $57 \%$ for first 10 hours and $37 \%$ for the more than 10 hours. This gave importance to the time spent in ICT education a significantly higher leverage. The ICT education time is exhibited to ICT hours $=\mathrm{f}$ (age, education type, gender, PC ownership, PC per student). In general, the perception is expressed by Rodriguez (2006) in an empirical study in a university environment. The issues are directly related to the age grouping, choice of subject with ICT or integrating ICT in the subject and having the ownership of necessary ICT equipment for each student.

\section{ICT Support Presence for Students}

The survey shows that the students use of ICTs, can positively impact their study habits. The activities highlights that $83 \%$ of students use computers daily to facilitate learning by positively stating on Assignment, 74\% on Internet surfing and another $83 \%$ on research work. The internet is becoming the medium of learning and research as stated by Bataineh and Baniabdelrahman (2005) that computers are used as a supplement to teaching and learning.

There is students are ware and request the institution to be able to provide more ICT facilities such as computer labs, better computers in the labs, have enough computers in the labsand to provide ICT support. 51\% student have opted to institution do not have enough computers in computer labs. This is in the laboratory class or otherwise the general computer labs where students spend time to do ICT related work. $66 \%$ students want more computers in their institutions. The rate of ICT supports provide is not much impressive since there is $36 \%$ okay service and $11 \%$ poor services to the students.

\section{ICT Usage in Students Performance}

The performance is significantly related to the amount of student using Internet. The priority is given as much as $41 \%$ for the amount of information obtained from other listed source such as TV, Print medium and Radio. The ICT is evaluated to provide best means of communication by the use of emails and internet for $70 \%$, then research of $44 \%$, for E-Commerce of $39 \%$ and billing, travel and 
entertainment of $7 \%$. This bring in the flexibility of ICT study by allowing better allocation of ICT activities and articulation of private and study life (Mbah, 2010).

Presence of Internet has made somewhat to strongly agreed that life is easier up to $82 \%$. The performance of student is directly influenced by the ICT in education and indirectly by the use of technological skills in ICT. The following relationship of Educational Performance $=\mathrm{f}$ ( Self Directed hours, ICT hours, Successful completion of Year 12/13).

The analysis refers to the academic performance of students having little relevance on the effectiveness of the use of ICT on the results if it is just focused in one institute than the 3 universities. The survey still focuses on the Educational Performance to be directly related to the Average Grade Point Average in previous Terms. This is very difficult to determine with $36 \%$ of the students were from first term students. The positive indicator is also stated by Twigg (2004), for empirically confirmed effective educational practices.

\section{ICT Infrastructure in Student Learning}

The Internet access is the major hurdle and majority of $64 \%$ students opted that "home" is the best place to access Internet. Another $21 \%$ preferred their university than the work place which is either restricted or not conducive for study. The Internet service providers are few in Fiji and most known one is Vodafone (liked 54\%), Unwired (29\%), Connect $(10 \%)$, Kidanet $(2 \%)$ and others. The access to Internet is most conveniently in obtained from the ISPs for $52 \%$ than the Net Cafes which are regarded as very expensive by at least $12 \%$ students.

The most familiar and easy way to work in ICT is through Social Network sites and this is supposedly confirmed by $88 \%$ student. Others also say that social networking helps in communications and making friends $(57 \%)$ and entertainment and professional activity of $83 \%$.The infrastructure was evaluated in the survey as student ratio to computers as 50:50 while records of $64 \%$ internet connection was okay with significantly high in $36 \%$ of the Computers not having Internet connects at all.

\section{Educational Competencies for Students in ICT Education}

The academics determine the systematic ways to analyze the use of ICT in the education through the implementation of policies. The educational concepts, theories and issues will be guided by the policy in place. The possible connections between the aspect of subject knowledge and its application in the policies and contexts are means to implement the ICT use in education. There were $43 \%$ times when Teachers will only have access to Computer facilities, $9 \%$ time used for administration purposes. Students merely had equivalent of $44 \%$ time for the computer labs or ICT facilities.

The value of academic systems needs to reflect well in the theories and concepts in education studies. The diversifying nature of learners and the complexities of learning process need to be prioritized. This can be simply in terms of awareness of context in which learning can take place. The digital divide is considered to overcome through the ICT in Education by $94 \%$. This is also taking in consideration for the different roles of participants in the learning process. The understanding of the structures and purpose of education process needs to be ranked as well.

Educational research and counseling skills demand the means of ICT use. This will enable the management of projects for the schools, management of educational programmes and foresee the educational needs and demands. Hence, this is one medium of leading and coordinating multidisciplinary education teams with the help of ICT. There are still concerns by students that $24 \%$ chance of ICT is not in use for the educational system.

\section{Other Support towards ICT in Education}

While the statistics is still significant for $16 \%$ students to say that they do not agree to the up to date ICT application and facilities present, they also agree on the insufficient computer labs of $49 \%$, institutes lack of support of $64 \%$ and there is need for Government to back up toward ICT development in Education and ICT education for 57\%.

Buabeng-Andoh (2012) believes that the government intervention in the university on majority developed countries has uplifted the standards of ICT in Education. The presence of authorizes will elevate ICT in education from one point to another.

\section{Conclusion}

The planning and vision in the overall goals for the presence of ICT in the education is a need. There has to be linkage between ICT in education policy and other policies where funding and expenditure for ICT in education has to be determined. The institutions and public private partnerships on ICT education required to be planned. The ICT infrastructure with regards to equipment, networking material, technical support, maintenance and electricity supply needs to be established well at the ground. The technical supports needs to look into new, old and junk materials.

The teachers in primary, secondary and tertiary level needs to be teacher training and professional development determining the teacher competencies in ICT related education. For this there is need to have leadership training, professional development and competency standards established. The skills and competencies need the staff to be well versed with ICT literacy and digital competency in 
formal and non-formal education system of vocational and higher education streams for the ICTs impact on education (Mikre, 2011).

The information systems setup as a backbone is required for the management of education system for digital content and digital learning and curriculum (Cuban, Kirkpatrick \& Peck 2001). The monitoring, assessment, research and development focus needs to be established. The evaluation and ICT use in assessment is necessary for success of ICT in education. The standards, ethics and delivery with health and safety requirements need to be sound with the ICT presence in education.
The trends in education can be feasible with the growing nature of technology in e-learning, m-learning, distance learning, community educations, early childhood education and issues such as data privacy and ICT policies. The provision of e-book and e-readers will be best catered for.

This study has finally elaborated with the statistics that this is one of the first ever survey in the tertiary sector where students exposure is evaluated in terms of ICT usage. Other pacific island nations with similar scale of ICT presence need to come together and see into students' involvement with ICT studies and usage in education at tertiary level.

\section{Annex A}

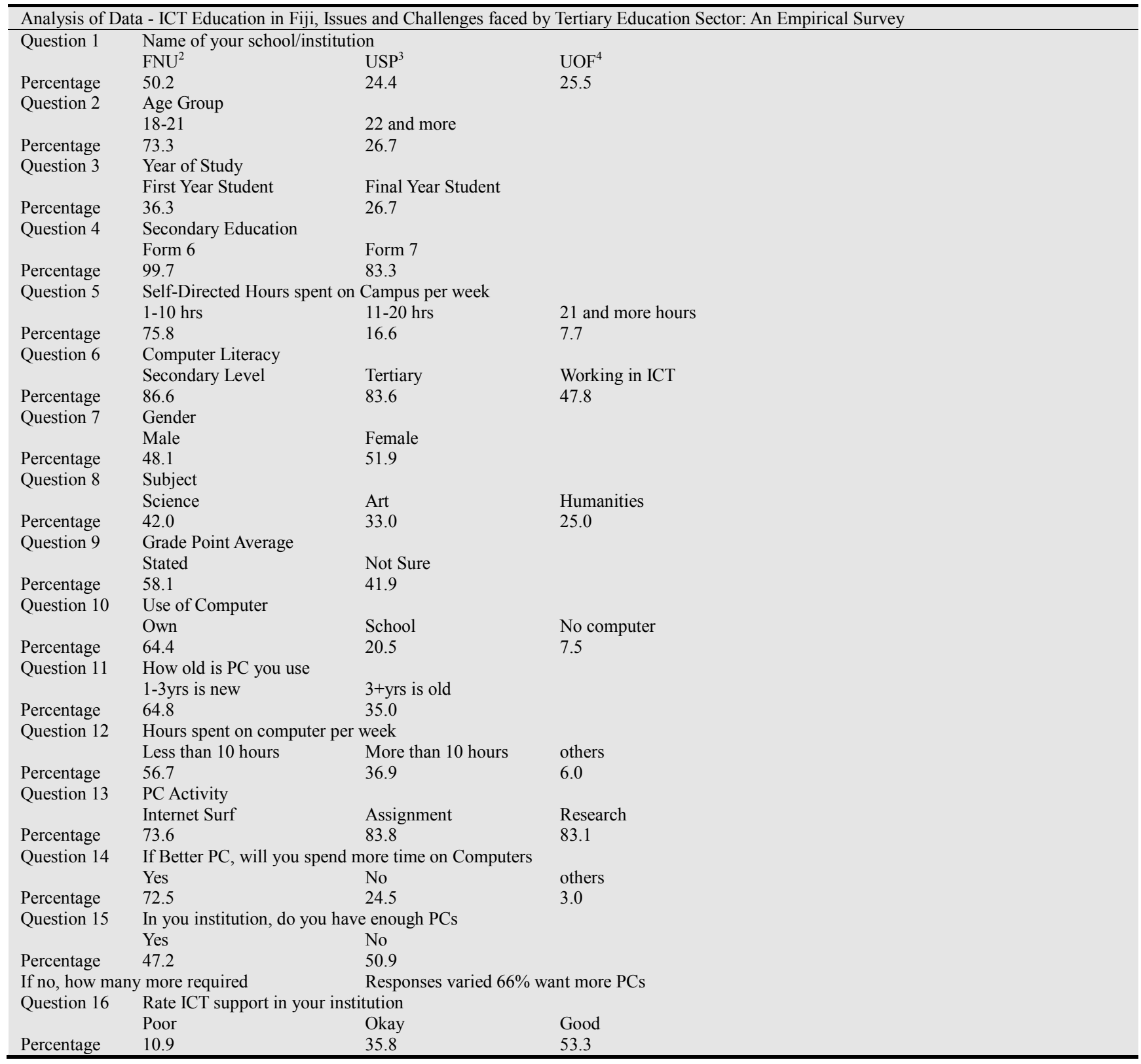

\footnotetext{
${ }^{2}$ FNU: Fiji National University

${ }^{3}$ USP: University of the South Pacific

${ }^{4}$ UOF: University of Fiji
} 


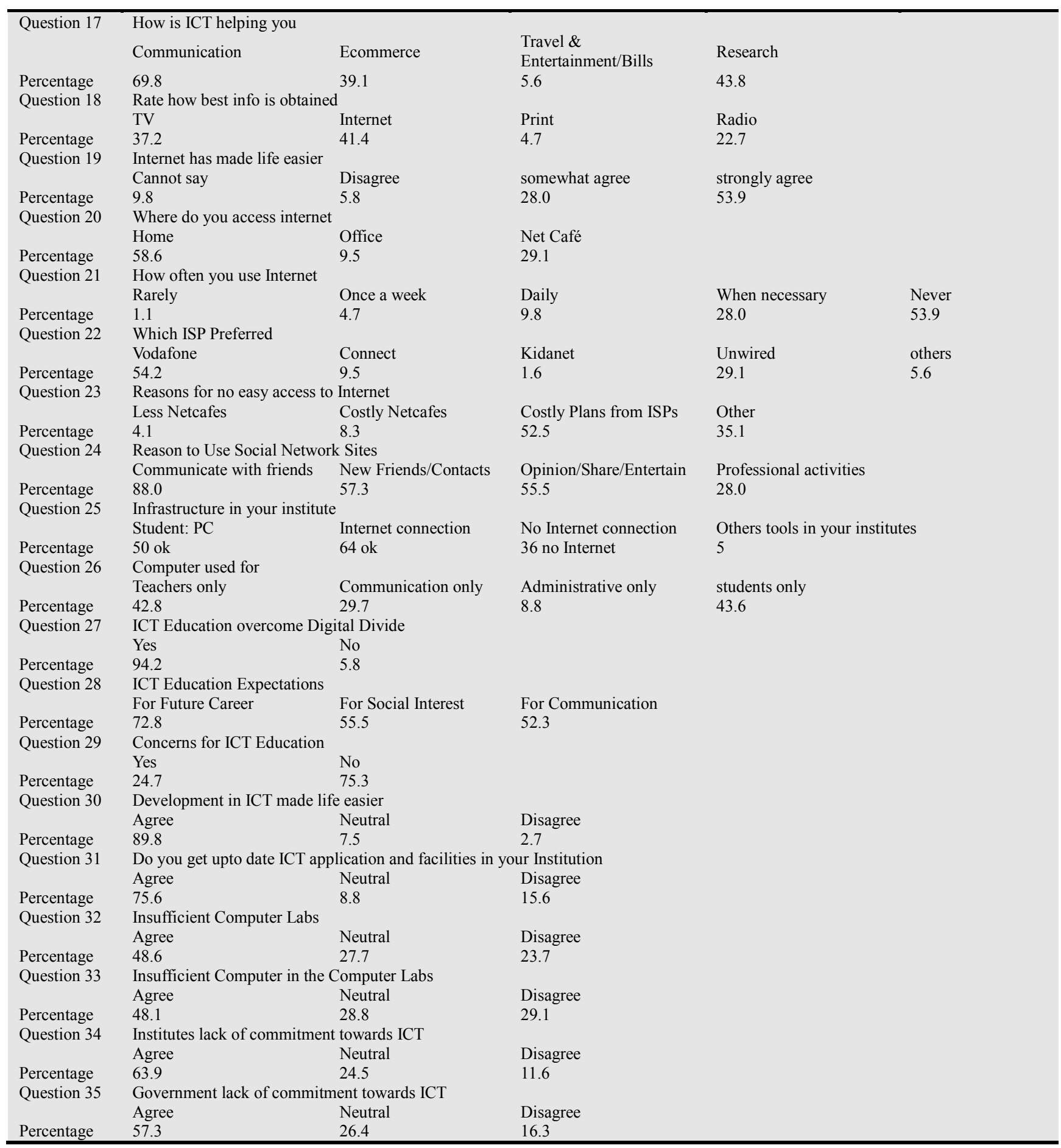

\section{References}

[1] Ajayi G. O. "African response in the ICT Revolution" pg 1 2002. URL: http://www.atssnet.org/docs/ajayi.pdf assessed online on 14th Jan 2013

[2] Anju S. \&Vikas S. "Role of ICT in Education of Ayurveda: A Review", International Research Journal of Pharmacy pg 662012 URL: www.irjponline.com

[3] Bataineh R.F. \&Baniabdelrahman A. A. "Jordanian EFL Students' Perceptions of their Computer Literacy",
International Journal Education in Development using Information and Communication Technology (IJEDICT), Volume 2 Issue 2, pg 35-50, 2005.

[4] Buabeng-Andoh C. "Factors Influencing Teachers' Adoption and Integration of Information and Communication Technology into Teaching: A Review of the Literature". International Journal of Educational and Development using ICT Volume 8 Issue 1 pg 136, 2012.

[5] Cuban L., Kirkpatrick H. \& Peck C. "High Access and Low use of Technology in High School Classrooms: Explaining an Apparent Paradox" American Educational Research Journal. Volume 38 no. 4 pg 816, 2001. 
[6] Hong K. \&Songan P. "ICTin the Changing Landscape of Higher Education in Southeast Asia" Australasian Journal of Educational Technology, Special Issue 8, 27 pg 1284, 2011.

[7] Hattangdi A. \&Ghosh A., "Enhancing the Equality and Accessibility of Higher Education through the use of Information and Communication Technology". Paper presented in 11th Annual Convention for the Strategic Management Forum, Kanpur India May 8-10, 2008.

[8] Jhurree V. "Technology Integration in Education in Developing Countries: Guidelines to Policy Makers", International Education Journal, edition 6 volume 4 pg 475, 2005 .

[9] Kuh, G., \& Nelson, T. "Student Experiences with Information Technology and their Relationship to Other Aspects of Student Engagement. Paper presented at the Annual Meeting of the Association for Institutional Research, Boston, MA. Pg 5-6, 2004.

[10] Larsen K. \& Vincent-Lancrin S. "The Impact of ICT on Tertiary Education: Advances and Promises" OECD/NSF/U. Michigan Conference 10-11 Jan 2005 pg 3, 2005.

[11] Marcelle, G. "Getting Gender into African IT Policy: A Strategic View", Gender and the Information Revolution in Africa, Rathgeber and Ofwona, pg 48-49, 2002.

[12] Mbah T. B. "The impact of ICT on students' study habits. Case study: University of Buea, Cameroon". Journal of Science and Technology Education Research Volume 1 Issue 5. Pg 110, 2010.

[13] Mikre F. "The role of Information Communication Technologies in Education: A review Article with emphasis on Computer and Internet". Ethiopia Journal of Education and Science Volume 6 no. 2 pg 5, 2011.

[14] Mlitwa N. B. "Technology for Teaching and Learning in Higher Education Contexts: Activity Theory and Actor Network Theory Analytical Perspective, International Journal of Education and Development using Information and Communication Technology, Issue 3 Volume 4 pg 54-70, 2007.

[15] Oliver R., "Creating Meaningful Contexts for Learning in Web-based Settings. In he proceeding of Open Learning pg
53-62,

2000.URL:

http://elrond.scam.ecu.edu.au/oliver/2000/ol.pdf accessed 11th Jan 2013

[16] Pak, L. "Some Policy Issues on ICT in Education", University Brunei Darussalam, 11, pg 133-140, 2006.

[17] Rodriguez C. E. G "Educative uses of ICT, Technological skills and Academic Performance of Venezuelan University student (Barineses) A causal perspective". International Journal of Education and Development using Information and Communication Technology. Volume 2 Issue 4 pg 36, 2006.

[18] Scheuermann F. "Conceptual Framework for Studying the Effect of ICT in Education" International Expert Meeting on ICT in Education Indicators, Busan, South Korea, 7-9 July 2009 pg 7

[19] Systems Approach for Better Education Results: The Use of ICT (SABER-ICT) URL: www.worldbank.org/education/saber-ict, accessed on 25th February 2013

[20] Twigg, C. A. "Improving learning and reducing costs: Lessons learned from round II of the Pew grant program in course redesign" Center for Academic

[21] Transformationpg 3, 2004.URL: http://www.center.rpi.edu/PewGrant/Rd2Less.html accessed on 31 st Dec 2012

[22] Trucana, M. "Knowledge Maps: ICTs in Education", ICTS and the Education MDGs, Information for Development Program, Washington, DC USA, 2005. URL:www.infodev.org/educationaccessed on 11th Jan 2013.

[23] U.S. Department of Education, Office of Planning, Evaluation, and Policy Development, "Use of Education Data at the Local Level from Accountability to Instructional Improvement", Washington, D.C. pg 40-46, 2010. URL:http://www.ed.gov/about/offices/list/opepd/ppss/report s.html\#edtech accessed on 25th Jan 2013

[24] Yusuf M.O. "Information and Communication Technology and Education: Analyzing the Nigerian National Policy for Information Technology" International Education Journal Edition 6 Volume 3 pg 317, 2005. 